ISSN: 0213-2087 eISSN: 2444-7080

DOI: http://dx.doi.org/10.14201/shhc201836161170

\title{
EDUCAÇÃO PARA DIREITOS HUMANOS: UMA PROPOSTA CRÍTICA
}

\section{Education for Human Rights: One Critical Proposal}

\author{
Carlos V. ESTÊVÃO \\ Universidade Católica Portuguesa (Braga) - Universidade do Minho \\ caestevao@braga.ucp.pt
}

Recepción: 27/04/2018 Revisión: 03/05/2018 Aceptación: 25/05/2018

RESUMO: O autor começa por caracterizar de uma forma genérica a educação actual, com relevância para a influência que as diversas escalas (global, regional, nacional e local) exercem no fenómeno educativo. Realça, ainda, a forma como a matriz institucional da escola se alterou face aos desafios da conjuntura actual. Num segundo momento, é apresentada uma concepção de educação em direitos humanos de cariz mais funcional e pragmática, para, depois, o autor sinalizar os traços mais relevantes de uma educação critica em direitos humanos, assente noutros pressupostos, noutra normatividade. No final, e de uma forma mais didáctica, o autor apresenta o decálogo de uma educação crítica em direitos humanos, que permanece radicalmente como uma educação politica.

Palavras-chave: Educação actual; direitos humanos; educação crítica em direitos humanos.

RESUMEN: El autor empieza por caracterizar, de manera genérica, la educación actual, pertinente a la influencia que las diferentes escalas (mundial, regional, nacional y local) juegan en el fenómeno educativo. Destaca también cómo el marco institucional de la escuela ha cambiado ante a los desafíos de la situación actual. En segundo lugar, se presenta una concepción de la educación en derechos humanos más práctica y pragmática, para, a continuación, señalar los rasgos más importantes de una educación crítica de los derechos humanos, sobre la base de otros supuestos, otra normatividad. Al final, y de una manera más didáctica, el autor presenta el decálogo de una educación crítica de los derechos humanos, que sigue siendo radicalmente una educación política. 
Palabras clave: educación actual; derechos humanos; educación critica en derechos humanos.

ABSTRACT: The author begins by characterizing, in a generic way, the current education, with relevance to the influence that the diverse scales (global, regional, national and local) exert in the educational phenomenon. He also highlights the way in which the school's institutional matrix has changed in the face of the current challenges. Secondly, a more functional and pragmatic conception of human rights education is presented, and the author then points out the most relevant features of a critical education in human rights, based on other presuppositions, in another normativity. In the end, and in a more didactic way, the author presents the decalogue of a critical education in human rights, which remains radically as a political education.

Key words: Current Education; Human Rights; Critical Education in Human Rights.

\section{A EDUCAÇÃO ATUAL}

A educação atualmente já não é o que era. Mudou de sentido. Com efeito, ela tem vindo a ser modificada por várias instâncias de coordenação que a condicionam. Desde logo, pelo Estado, mas também pelo mercado e pela comunidade. Isto significa que estas instâncias estão a ter um papel e um peso diferentes nas atividades de regulação, de oferta e de financiamento da educação.

Por outro lado, a influência das diversas instituições na educação deixou de restringir-se a uma escala, tradicionalmente a nacional. Com efeito, tão importante como esta, a relevância das escalas global, regional e local deverá ser igualmente considerada para melhor compreendermos o fenómeno educativo. Por outras palavras, e tal como afirmou Dale (2010), no artigo intitulado Sociologia da Educação e o Estado após a globalização, a governança educacional (isto é, a combinação de atividades, atores e escalas) tem uma natureza multiescalar e as políticas educacionais não podem mais ser vistas como reserva exclusiva dos Estados-nação individualmente considerados.

Perante as vicissitudes por que tem passado a educação nestes tempos neoliberalizados, podemos afirmar que hoje ela tem sido particularmente acarinhada pelo mercado, transformando a sua natureza, fazendo valer o tipo de educação que "conta». É esta, de facto, aquela que nos tempos que correm verdadeiramente importa, menosprezando outras educações, que não «contam» ou que «contam menos» ${ }^{1}$.Dentro deste espírito contabilístico, a educação pelas competências é a superstar, porque tem o efeito de nos tornar particularmente maleáveis, flexíveis, plásticos (de corpo e alma) e porque nos incute a ideia de que, para sermos competentes, teremos de ser eternos aprendentes, pois só deste modo nos tornaremos

1. Lima, Licínio C.: "O paradigma da educação contábil. Políticas educativas e perspectivas gerencialistas nonensino superior em Portugal», Revista Brasileira de Educação, 4, 1997, 43-59. 
mais portáteis e, de forma mais crua (ou cruel), mais vendáveis. Quanto ao contingente dos desajeitados, dos inadaptados, dos incompetentes, há que canalizá-los para vias alternativas, pelo que um dos verdadeiros problemas do sistema educativo tem a ver com o problema de "tratamento destes resíduos".

Como é fácil de intuir, a escola não poderia ficar incólume aos desafios advindos desta conjuntura complexa. Assim, é um facto que ela foi invadida por outros públicos, por outras éticas, por outras justiças, por outras culturas. E perdeu o monopólio da grande cultura que ela ministrava e administrava. Além disso, nesta sociedade de comunicação de massas, ela perdeu o seu estatuto de verdadeira depositária das chaves que abriam o mundo aos jovens. Como nos diz Dubet ${ }^{2}$, hoje os alunos "podem abrir-se ao mundo sem passar pela escola".

Isto significa que, institucionalmente, a matriz tradicional da escola (que assentava na uniformidade, na homogeneidade, na unicidade) se alterou também e que os alunos já não entram na escola com a mesma devoção de antigamente; ou seja, dessacralizou-se. Por outro lado, estruturalmente, a escola tornou-se mais plural, acolhedora de outras lógicas, de outras racionalidades (cívicas, mas também domésticas, empresariais, mercadorizadas, globais...), transformando-se verdadeiramente num mundo onde coexistem vários "mundos", ou seja, várias visões do mundo, dos valores, da educação e da escola ${ }^{3}$.

E neste modo de compreender a escola, como ficam os direitos? Logicamente que os direitos humanos são vividos de forma não coincidente. Explicando melhor: se encararmos a escola como uma mcEscola e a educação como uma atividade mercantil, por exemplo, os direitos humanos passam a ser vistos dentro de uma visão em que o importante são os direitos individuais, pelo que ter direitos se torna um assunto do foro privado, dependente de condições que cada um possui; os direitos, neste contexto, não passam, afinal, de títulos de posse. Aqui poderíamos situar o modelo de educação tão em voga do "capital humano", assente numa perspetiva economicista das relações sociais, e em que o conceito multiuso dos direitos humanos ${ }^{4}$ se encaixa perfeitamente bem.

Se, pelo contrário, compreendermos a escola como escola sociocrítica e a educação como realização cidadã, os direitos emergem naturalmente dentro de uma visão igualitária, cosmopolítica (melhor que cosmopolita), sendo interpretados como universais (mas não absolutos), indivisíveis, interdependentes e interrelacionados, abrangendo os direitos civis e políticos mas também os direitos económicos, sociais, culturais e ambientais.

2. Dubet, François: Éducation: pour sortir de l'idée de crise. Actes de l' université d'automne: Grande pauvreté et réussite scolaire, 28-30, octobre, 2002. <http://eduscol.education.fr/cid45926/ education\%C2\%A0-pour-sortir-de-l-idee-de-crise.html> (acesso em 23 de abril de 2017).

3. ESTÊvão, Carlos V.: Educação, justiça e democracia. Um estudo sobre as geografias da justiça em educação. S. Paulo: Cortez Editora, 2004.

4. Matlary, J. H.: Derechos humanos depredados. Hacia una dictadura del relativismo. Madrid: Ediciones Cristiandad, 2008. 
Estes são apenas dois modos de ver a escola e os direitos humanos, expostos de modo sucinto e de forma quase dicotómica, mas existem outras formas de entendê-los e de explicá-los, apesar de não ser oportuno, neste artigo, avançar mais.

\section{EduCAÇÃO EM DiReitos humanos (EDH)}

Não obstante a escassez de propostas, quero realçar, até pelo seu pioneirismo, a de Tibbitts ${ }^{5}$, que sugere três modelos para a compreensão da prática contemporânea da EDH, a partir da pirâmide da aprendizagem:

1. Valores e consciencialização. Tem como foco a transmissão de conhecimentos básicos sobre questões relativas aos direitos humanos e o incentivo à sua integração em valores públicos. A estratégia pedagógica fundamental passa pelo compromisso.

2. Responsabilidade ou prestação de contas. Aqui encontram-se as formas em que as responsabilidades profissionais envolvem diretamente a monitorização das violações de direitos humanos e a sua defesa perante as autoridades competentes ou a assunção de cuidados especiais para proteger os direitos das pessoas.

3. Transformação. Este modelo capacita-nos a reconhecer abusos relacionados com os direitos humanos e compromete-nos com a sua prevenção. O programa pode incluir desenvolvimento de lideranças, formação e resolução de conflitos, formação vocacional...

Para além da valia intrínseca desta proposta, prefiro analisar esta problemática a partir de outros dois modelos: um, mais funcional aos intentos do poder ou dos poderes instituídos, ou seja, em termos habermasianos, um modelo que pressupõe os direitos humanos colonizados pelo sistema; e outro, mais assumidamente crítico, mais abrangente e inspirado nas teorias e pedagogias críticas, que realça os valores da convivência, da deliberação, da comunicação.

\subsection{Educação útil em direitos bumanos}

Tenho vindo a defender ultimamente que há uma educação em direitos humanos útil e muito funcional para endireitar os direitos humanos e, consequentemente, para nos endireitar a todos nós enquanto humanos.

5. Tiвbiтts, Felisa: "Understanding what we do: emerging models for human rights education", International Review of Education, 48 (3-4), 2002, pp. 159-171, 2002. 
Trata-se de um tipo de educação em direitos humanos sintonizado com os tempos anormais de hoje (Estêvão, 2015) e que se apresenta como uma espécie de muleta ao serviço de intuitos desenvolvimentistas do capital humano.

$\mathrm{Na}$ verdade, quem defender uma educação de qualidade medida, não pelos ideais de justiça social ou de direitos humanos, mas pelo nível de formação e desenvolvimento do capital humano ${ }^{6}$, poderá ter na educação em direitos humanos, por mais estranho que pareça, uma serviçal dedicada.

Por outro lado, e como vimos no ponto anterior, hoje, a educação que interessa é sobretudo a das competências, porque nos torna aptos para todo o serviço, ou, por outras palavras, a que potencia a nossa portabilidade e vendabilidade. Se para tal, tivermos de nos transformar em eternos aprendentes, dentro dessa ideologia encantatória como é a aprendizagem ao longo da vida, nada teremos a perder, porque o cidadão hoje se define também pelo investimento perpétuo na aprendizagem.

Até em termos de justiça, a educação deve marcadamente tornar-se meritocrática; ou seja, recompensar os talentosos, os melhores, porque hoje a justiça se define essencialmente pela sua eficiência e eficácia. Na verdade, ser justo, hoje, é sinónimo de ser eficiente e eficaz.

Dentro destas "ideologias de conveniência», a educação em direitos humanos ajustada é aquela, repito, que nos endireita e endireita os direitos humanos de acordo com os valores e as ideologias monocromáticas dominantes.Mas, antes de avançar na caracterização mais pormenorizada deste tipo de educação em direitos humanos, o que se pretende dizer com «endireitar os direitos»? Fundamentalmente significa que os direitos são entendidos como próteses ou paliativos ao serviço da sustentação do atual sistema, evitando más formações ou desvios ao que oficialmente é entendido como política, social e culturalmente correto; significa também que os direitos são exigências febris de consumidores ávidos de igualdade, uma vez que, sintonizados com a nova sociedade do consumo que os torna visíveis, belos e úteis, pretendem marcar pelo consumo o seu estatuto igualitário; finalmente, "endireitar os direitos» pode significar a utilização dos direitos como ferramentas multiusos para nos tornarmos mais e melhores cidadãos de mercado, com deveres primeiros para com os «bezerros de oiro", tão idolatrados no mundo neoliberalizado.

Atendo-me a este último aspecto, considero que, se hoje a ordem dominante ou o critério redistributivo dominante é mercado, que apela a várias estratégias para nos mantermos "grandes» e bem sintonizados com as exigências do "novo espírito capitalista», então o que interessa é mobilizar, de facto, o conceito funcional ou "multiuso" dos direitos humanos, sujeito aos humores políticos e aos diversos interesses. Isto aponta para a necessidade e urgência de os direitos serem

6. ESTÊvão, Carlos V.: «Justiça social e modelos de educação: para uma escola justa e de qualidade», Revista Diálogo Educacional, vol. 16, n. ${ }^{\circ} 47,2016$, pp. 37-58.

7. Boltanski, Luc \& Chiapello, Ève: Le nouvel esprit du capitalism. Paris: E. Gallimard, 1999. 
separáveis, divisíveis, deformáveis, desarticuláveis (tal como muitos dos produtos fabricados por multinacionais de equipamento e mobiliário), a bel-prazer das exigências da economia (que anda algo enlouquecida nos tempos que correm) e das nossas teorias sobre o Outro, para, deste modo nos mantermos rentáveis e sempre em forma, independentemente de tal concepção dos direitos nos deixar a boiar à superfície dos critérios morais e dos valores.

A partir deste enquadramento, uma educação útil e funcional em DH ou uma educação às direitas deve servir, entre outros aspectos: para nos empoderar pela via das competências, tornando-nos moldáveis; para nos transformar em eternos aprendentes, ainda que, por vezes, pouco cidadãos; para nos tornar mais vendáveis, em sintonia com as exigências dos nossos tempos, aumentando a nossa portatibilidade e a nossa condição de boa mercadoria; para nos transformar em sujeitos coercivamente individualizados; para reforçar as medidas certas, os corpos e mentes certos; para impor a política de homogeneidade cultural que valoriza o direito à indiferença; para se tornar um lenitivo para os vencidos do sistema e da ordenação natural das coisas; para purificar o sistema (no caso da educação, esta tem o seu sistema próprio de canalização e tratamento de inertes); para impor-nos pacificamente a ideia de que atingimos o prazo de validade (até porque, como nos diz Bauman ${ }^{8}$, os consumidores são "Viciados no curto prazo»), tornando-nos, por isso, sobras humanas.

Em síntese, embora a educação em direitos humanos que acabei de caracterizar não emirja nos discursos normais nem nas teorias que versam os direitos humanos com esta clareza e frontalidade, considero que frequentemente ela tende a ser a mais acarinhada na prática, porque é a fórmula mais domesticada e domesticável da educação em direitos humanos. É, por assim dizer, a solução mais indolor, lógica e aparentemente mais neutral de uma educação adaptada aos tempos «líquidos", na expressão de Bauman ou, como se diz hoje, aos tempos da pós-verdade.

\subsection{Educação crítica em direitos bumanos}

Um educação crítica em direitos humanos, que aqui defendo, inspira-se noutros pressupostos, noutra normatividade, enfim, noutras abordagens desenvolvidas por vários autores defensores das teorias e das pedagogia críticas, que, no fundo, se constituem em desafios às grandes narrativas do capitalismo, do racionalismo científico, da burocracia, do colonialismo, do liberalismo, do determinismo económico, entre outras.

8. Bauman, Zygmunt: Vidas a crédito. Rio: Zahar. Editor, 2010, p. 210. 
Tendo presente o que já escrevi ${ }^{9}$ e baseando-me ainda em McLaren ${ }^{10}$ e em McLaren \& Kincheloe ${ }^{11}$, uma educação em direitos humanos crítica

não pode descurar os contextos sociais, culturais e políticos em que os direitos necessariamente nascem, se desenvolvem e se transformam, reconhecendo, ainda, como seu ambiente natural, a democracia como direitos humanos. Depois, EDH deve assumir a dimensão política, rompendo deste modo com a concepção de direitos como uma esfera separada e prévia à acção política democrática, e deve recuperar a dimensão social que reconhece e entende os direitos como processos e práticas sociais de luta pela dignidade humana, aspecto este que decorre também da nossa proposta de democracia como direitos humanos.

Tendo presente este posicionamento, referia mais à frente o impacto de uma educação em direitos humanos crítica para a aprendizagem:

Ao nível da aprendizagem, esta perspectiva da EDH encara-a como uma forma que visa proporcionar aos estudantes poder e controlo sobre a própria aprendizagem, favorecendo várias fórmulas dessa mesma aprendizagem, ao mesmo tempo que a pensa como uma forma também de solidariedade social. A EDH crítica deve, por isso, desmontar o modo como a estrutura educativa e o currículo têm efeito na moldagem do sujeito de direitos, proporcionando aos estudantes os métodos mais apropriados para analisar a própria realidade educativa e social.

As implicações desta abordagem eram já então claras:

A abordagem crítica da EDH tem ainda implicações a outros níveis, para além dos relacionados com a pedagogia de aprendizagem e dos currículos: desde logo, ao nível da concepção de escola, reconfigurando-a como uma organização democrática, com potencialidades cidadãs; ao nível de uma concepção emancipadora do próprio conhecimento; ao nível da investigação que deve ter presente a articulação entre educação, ideologia, produção e poder, interrogando-se sobre o modo como a reprodução social se produz na reprodução cultural, mediante a imposição e ocultação, produção e consumo de recursos simbólicos.

Então, uma educação crítica para os direitos humanos deve claramente acentuar vários princípios de vida, que devem nortear a educação e a pedagogia. De uma forma didáctica, eu resumiria esses princípios a um decálogo, que ecoa como um anúncio. A educação em direitos humanos:

9. Estêvão, Carlos V.: «Democracia, direitos dumanos e educação. Para uma perspectiva crítica de educação para os direitos humanos", Revista Lusófona de Educação, n. 17, 2011; ver também CARvalHo, Elizete \& Estêvão, Carlos V.: "Pedagogia crítica e direitos humanos: fundamentos para uma proposta pedagógico-crítica em direitos humanos», Revista Ensaio, vo. 21, n. ${ }^{\circ}$ 80, 2013 (jul./set.), pp. 405-432.

10. Mclaren, Peter: Pedagogia crítica y cultura depredadora. Políticas de oposición en era posmoderna. Barcelona: Paidós, 1997

11. Mclaren, Peter \&; Kincheloe, Joe L. (orgs.): Pedagogía crítica: de qué hablamos, dónde estamos. Barcelona: Graó, 2008. 
i) está ligada à transformação social no mundo para uma sociedade mais justa e igualitária;

ii) mobiliza um conceito de educação que entra no combate à injustiça, à dominação, à opressão e à violência, mais ou menos institucionalizadas;

iii) favorece o diálogo com os sem-voz, os marginalizados, os excluídos, os pobres, dando ferramentas para desmascarar e lutar contra políticas de poder injustas e cruéis;

iv) articula-se com as lutas pela dignidade da pessoa e do planeta, contra a discriminação, a intolerância, a corrupção e a impunidade, sem perder de vista o resgate da memória histórica;

v) fomenta a interdependência, a cooperação e a solidariedade mundiais, dentro de uma visão cosmopolítica e integral dos direitos e da justiça;

vi) promove a democracia como direitos humanos para que, entre outros aspectos, todos aprendam a ser governados mas também governantes com vista ao exercício activo e ao aperfeiçoamento da própria democracia;

vii)exercita o pensamento como conhecimento e como reconhecimento do outro, fomentando o diálogo, a comunicação e a aprendizagem entre culturas;

viii) pratica a ética da critica, da indignação, lutando, por vezes, contra a educação e os seus processos de normalização e de naturalização;

ix) mobiliza a linguagem da possibilidade, ou seja, a ética da justiça e do cuidado, em ordem à transformação social, cultural e institucional e, finalmente, à paz;

x) concretiza-se no dia a dia em práticas de perdão, de prevenção de violações, de ajuda, de testemunho, de solidariedade, uma vez que o acto pedagógico deve ser entendido como compromisso social e comunitário.

Assim sendo, a educação crítica em direitos humanos é essencialmente uma política de vida e uma ética global, que requer, entre outros aspectos, o resgate ético-político da própria educação contra o autoritarismo, a tecnocracia, a eficácia sem deliberação, a instrumentalidade gerencialista ${ }^{12}$, a coisificação ou a objectificação; que requer, ainda, uma educação militante que luta contra a vulnerabilidade institucional favorecedora de práticas de dominação, de privilégio, de opressão, de exploração e de exclusão; que requer, enfim, uma visão educação cosmopolítica, que considera o outro, esteja ele onde estiver, um sujeito de direitos.

Em certo sentido, a educação critica em direitos humanos é o momento da confissão do nosso amor pelo mundo, pelo Outro e a assunção da nossa responsabilidade por eles. Daí a educação em direitos humanos ser eminentemente uma

12. VÁzQuez Andrade, Piedad Magdalena: Teoría crítica de la educación y derechos humanos: lineamientos para una propuesta educativa. León: Universidad de León, 2006; e EsTÊvão, Carlos V.: “Democracia política, democracia escolar e educação para os direitos humanos", Revista Educação (Porto Alegre, impresso), v. 36, n. 1, 2013 (jan./abr.), pp. 28-34. 
educação de empoderamento e de compromisso, uma educação politica, construtora de sujeitos de direitos.

\section{REFERÊNCIAS BIBLIOGRÁFICAS}

Bauman, Zygmunt: Vidas a crédito. Rio: Zahar. Editor, 2010.

Boltanski, Luc \& Chiapello, Ève: Le nouvel esprit du capitalism. Paris: E. Gallimard, 1999.

CARvalho, Elizete \& EstÊvão, Carlos V.: «Pedagogia crítica e direitos humanos: fundamentos para uma proposta pedagógico-crítica em direitos humanos", Revista Ensaio, vo. 21, n. ${ }^{\circ} 80,2013$ (jul./set.), pp. 405-432.

DuBet, François: Éducation: pour sortir de l'idée de crise. Actes de l' université d'automne: Grande pauvreté et réussite scolaire, 28-30, octobre, 2002. <http://eduscol.education. fr/cid45926/education\%C2\%A0-pour-sortir-de-l-idee-de-crise.html> (acesso em 23 de abril de 2017).

Estêvão, Carlos V.: "Democracia política, democracia escolar e educação para os direitos humanos", Revista Educação (Porto Alegre, impresso), v. 36, n. 1, 2013 (jan./abr.), pp. 28-34.

Estêvão, Carlos V.: «Democracia, direitos dumanos e educação. Para uma perspectiva crítica de educação para os direitos humanos", Revista Lusófona de Educação, n. ${ }^{\circ}$ 17, 2011.

EsTêvão, Carlos V.: Educação, justiça e democracia. Um estudo sobre as geografias da justiça em educação. S. Paulo: Cortez Editora, 2004.

Estêvão, Carlos V.: "Justiça social e modelos de educação: para uma escola justa e de qualidade», Revista Diálogo Educacional, vol. 16, n. ${ }^{\circ}$ 47, 2016, pp. 37-58.

Lima, Licínio C.: "O paradigma da educação contábil. Políticas educativas e perspectivas gerencialistas nonensino superior em Portugal», Revista Brasileira de Educação, 4, 1997, 43-59.

Matlary, J. H.: Derechos humanos depredados. Hacia una dictadura del relativismo. Madrid: Ediciones Cristiandad, 2008.

Mclaren, Peter \&; Kincheloe, Joe L. (orgs.): Pedagogía crítica: de qué hablamos, dónde estamos. Barcelona: Graó, 2008.

McLaren, Peter: Pedagogia crítica y cultura depredadora. Políticas de oposición en era posmoderna. Barcelona: Paidós, 1997.

TiввітTs, Felisa: «Understanding what we do: emerging models for human rights education", International Review of Education, 48 (3-4), 2002, pp. 159-171, 2002.

VÁzQuez ANDRADE, Piedad Magdalena: Teoría crítica de la educación y derechos humanos: lineamientos para una propuesta educativa. León: Universidad de León, 2006. 
